\title{
The Diagnostic Value of Neutrophil-Lymphocyte Ratio in Diagnosis of Autism Spectrum Disorders
}

\author{
Nurmalia PS ${ }^{1}$, Yudianita $K^{2}$, M. Rafli Haiqal ${ }^{3}$, M. Fadill Akbar ${ }^{3}$ \\ ${ }^{1}$ Department of Clinical Pathology, Faculty of Medicine, Sriwijaya University/Moh. Hoesin Hospital Palembang, Indonesia. \\ E-mail:nurmaliaps31@gmail.com \\ ${ }^{2}$ Department of Pediatrics, Faculty of Medicine, Sriwijaya University/Moh. Hoesin Hospital Palembang, Indonesia \\ ${ }^{3}$ Faculty of Medicine, Sriwijaya University
}

\begin{abstract}
Autism Spectrum Disorder (ASD) is a complex neurodevelopmental disorder, progressive disruption of brain development and synaptic connections, which causes impaired communication and behavioral disorders. However, the etiology is unknown. A damaged perinatal environment causes chronic nerve inflammation in genetically susceptible children of ASD, dysregulation of the immune system, which leads to ASD. The ratio of Neutrophil to Lymphocyte (NLR) as one of the markers of inflammation is frequently associated with inflammation-related psychiatric diseases and is potentially used as a diagnostic instrument. A cross-sectional study was carried out from June to November 2019 by using medical records of Outpatients with growth and development disorders and ASD and involving 69 children. The diagnosis of ASD was confirmed by the fifth edition Diagnostic and Manual of Mental Disorders criteria (DSM-V). A routine hematology test was carried out with a flow cytometry method. Diagnostic tests were performed in 43 children with developmental disorders (mean NLR 1.01 \pm 0.07 ) and 26 ASD children (mean NLR 1.02 \pm 0.06 ), with a cut-off value of 0.68 . Sensitivity, specificity, positive predictive value, negative predictive value and accuracy of NLR were $84.62 \% ; 27.9 \% ; 41.51 \% ; 25 \%$; and $50.2 \%$, respectively. Neutrophil to lymphocyte is sensitive to diagnose ASD but its accuracy is low. Immune dysfunction and complex neurodevelopmental disorders that are affected by chronic inflammation play a role in the occurrence of ASD. Other inflammatory markers are needed to improve the accuracy of laboratory tests to diagnose ASD.
\end{abstract}

Keywords: Autism spectrum disorders, neutrophil to lymphocyte ratio, DSM-V

\section{INTRODUCTION}

Autism, or Autism Spectrum Disorder (ASD), is a neurodevelopmental disorder characterized by disturbances in social interaction and communication, along with behavioral patterns and interests that are often limited and repetitive. ${ }^{1}$ The prevalence of autism in the world is increasing. Until 2000 , the prevalence of autism was 2-5 to $15-20$ in 1000 births, $1-2$ in 1000 world population. The Autism Society of America (ASA) data in 2000 showed there were 60 cases per 10000 births, with a total of 1:250 population. Meanwhile, in the 2001 Centers for Disease Control and Prevention (CDC) USA data showed the ratio between cases and residents of 1:150, while that in the USA/UK that was 1:100. In 2012 and 2014 CDC data showed that 1:88 and 1:68 children in the USA had autism, respectively. ${ }^{2}$ In March 2012 the US CDC issued a press release that described the results of a long-term study on the annual prevalence rate of autism in 8 year old children. They reported that 1 of
88 children aged 8 years had been diagnosed with autism in or before 2008. This represented a 78\% increase from the estimation in 2004. World Health Organization (2018) estimated that 1 of 160 children suffered from ASD, and the prevalence continues to increase. ${ }^{4}$ However, there has been no definitive data of its prevalence in Indonesia. It is estimated that the incidence and prevalence of ASD are two new cases per 1000 population per year and 10 cases per 1000 population. Because the population of Indonesia is 237.5 million with a population growth rate of $1.14 \%$, it is estimated that people with ASD in Indonesia are 2.4 million people with an additional 500 new patients/year. ${ }^{2,4}$

Autism is a complex developmental disorder in children which is influenced by many factors, including genetic, environmental, immune system disorders, and inflammation. ${ }^{5}$ Inflammation is one of the causes of system immune dysregulation and neuroinflammation. Neuroinflammation can impair brain tissue through several mechanisms, including plaque formation, abnormal neuron growth, and 
increased release of proinflammatory cytokines. ${ }^{6}$ Inflammation occurs when the cytokines/mediators are released in extracellular fluid. Cytokines modulate brain function so that inflammation occurs as a response of the brain. There are increased TNF- $\alpha$ and IL- 6 levels both in the blood and brain of Autistic patients. High levels of proinflammatory cytokines will trigger chronic neuroinflammation in autism. ${ }^{5,7}$

Neuroinflammation has been associated with many neurological and neuropsychiatric diseases. ${ }^{5}$ Cytokines have been shown to regulate the growth and cell proliferation of neuronal tissue and to modulate host responses to infection, injury, inflammation, and diseases with uncertain etiology. The dynamic expression of different cytokines can modify immune system function; increased levels of interferon-gamma (IFN- $\gamma$ ) and IL-6 can induce inflammation, whereas increased production of (TGF- $\beta$ ) can negatively regulate inflammation. Many recent studies have demonstrated that the levels of various inflammatory cytokines differ in the blood mononuclear cells, serum, plasma, brain tissue, and cerebrospinal fluid of autistic subjects compared with normal subjects, which might impair immune capacity in the Central Nervous System (CNS) reported in children with autism; in particular, reduced cytotoxic activity and elevated levels of certain pro-inflammatory cytokines produced by peripheral blood mononuclear cells, such as tumor necrosis factor (TNF- $\alpha$ ) and IL-1 $\beta$, have been shown to disrupt neurodevelopment. ${ }^{8}$ IL- 6 and TNF- $\alpha$ two pro-inflammatory cytokines, are found in high amounts in the brain, causing disruption or decrease of adhesion and neuronal migration, which results in disruption of the blood-brain barrier that functions to maintain normal homeostasis of the central nervous system. Chronic neuroinflammation is one of the causes of autism disorders in children. Autism is also referred to as a neurodevelopmental disorder.

Immune dysfunction that causes neuroinflammation has been studied in many ways as one of the etiologies of ASD, although no exact mechanism is known. An increased inflammatory activity in children with ASD is demonstrated by the increase in pro-inflammatory cytokines. Increase of pro-inflammatory cytokines was found in the plasma of 97 treatment-free and healthy children (aged 2 to 5 years) with ASD, who were recruited as case controls compared to children of the same age with developmental disorders. ${ }^{9}$ In addition to plasma, an increase of pro-inflammatory Th-2 cytokines in lymphocyte cells was also found in peripheral blood mononuclear monocyte cells of twenty children (from ages 3 to 10 years) with ASD compared to controls with normal development according to their age. ${ }^{10}$ Both Th1 and Th2 cytokines have been reported to increase in ASD children, and most recently, increased IL-1 $\beta$, IL-6, IL-17, IL-12p40, and IL-12p70 levels were found in 17 children (3-9 years) with a clinical diagnosis of ASD compared to 15 age children with normal development. ${ }^{10,11}$

The Endocannabinoid (EC) system is a complex network of neurotransmitters of the lipid pathway composed of arachidonic acid derivatives expressed in the central and peripheral nervous systems. Besides autism, the EC system is also involved in several other psychiatric disorders (i.e. anxiety, severe depression, bipolar disorder, and schizophrenia). This system is a major regulator of metabolism and cellular pathways involved in autism, such as food intake, energy metabolism, and immune system control. Early studies with animal models showed that changes in the brain EC system were found. Autism is also characterized by dysregulation of the immune system including changes in the differentiation of monocyte and macrophage responses and abnormal levels of cytokines and T lymphocytes. Cellular, monocyte, and macrophage the EC system dysfunction show that mRNA and $C B 2$ receptor protein (G-protein-coupled cannabinoid receptor (GPCR) type 1 (CB1)) and EC enzymes are significantly regulated in immunological disorders related to autism. ${ }^{12,13}$ Monocyte and lymphocyte macrophage cells are derived in-vitro from individuals with ASD with dysregulation of the EC system. This indicates the involvement of the EC system in autism-related to immunological disorders because monocytes and lymphocytes are cells responsible for the inflammatory response. ${ }^{13,14}$

Epithelial cell-derived neutrophil-activating peptide 78 (ENA-78) is a chemokine that can attract and activate neutrophils. In autism, there is a disfunction of immunity and neuroinflammation that triggers an inflammatory response by inducing neutrophil infiltration. Significantly higher ENA-78 levels were found in children with autism compared to healthy children. ${ }^{15}$

Neuroinflammation is one of the causes of ASD. Neutrophils, monocytes, and lymphocytes play an important role in the inflammatory process. A routine hematological test can be used to improve the accuracy of the diagnosis of ASD, due to its lower cost and simple use. Ashwood et al. found a higher absolute number of B cells and natural killer cells in children with 
autism compared to controls. ${ }^{16}$ The NeutrophilLymphocyte Ratio (NLR) has been extensively studied in association with psychiatry that occurs due to neuroinflammation. Neutrophil-lymphocyte ratio was investigated as a predictive and prognostic parameter in several psychiatric diseases associated with schizophrenic inflammation, bipolar disorder, and major depressive disorder. ${ }^{17-19}$ Neutrophil to lymphocyte ratio is known to have a negative correlation with ASD and its severity. ${ }^{20}$ It is important to determine the accuracy of NLR in ASD as an inexpensive, simple, and practical laboratory test for inflammation.

\section{METHODS}

This study was a diagnostic study with a crosssectional approach to determine the accuracy of NLR for diagnosis of autism spectrum disorders in Outpatients at the Pediatric Social Development Clinic at dr. Mohammad Hoesin Hospital, Palembang. The population in this study was patients aged 18 months -18 years with growth disorders and ASD.

The sample size in this study was determined using a diagnostic research formula with the output of the Area Under Curve (AUC). The number of samples obtained from the formula was 69 patients.

The diagnosis of ASD was carried out by pediatricians, based on criteria of DSM-V (Diagnostic and Statistical Manual of Mental Disorders, Fifth Edition (DSM-V)) in 2013 or ICD-10 issued by WHO in 1993 (American Psychiatric Association, 2013). A complete hematologic test was performed with a hematology analyzer using the flow cytometry method to obtain absolute neutrophil and lymphocyte count from the device. Also, the neutrophil/lymphocyte ratio was obtained from the division of the percentage of neutrophils by the percentage of lymphocytes.

Medical record data were analyzed from January to October 2019. Complete data were taken if the inclusion and exclusion criteria were met. Patients with suspected acute or chronic infection, allergies, and malignancies were excluded from this study. Data were collected and processed using statistical software.

This study was approved by Health Research Ethics Committee of the Faculty of Medicine, Sriwijaya University and Mohammad Hoesin Central General Hospital (number 560/kepkrsmhfkunsri/2019).

\section{RESULTS AND DISCUSSION}

The research data were taken from medical records of patients with differential diagnosis or a diagnosis of autism monitoring from January to October 2019. Subjects in this study were 69 people, consisting of 43 patients with developmental/ non-ASD and 26 patients with a diagnosis of ASD.

Table 1. Demographic characteristics of research subjects $(n=69)$

\begin{tabular}{|c|c|c|c|c|}
\hline \multirow{2}{*}{ Characteristics } & \multicolumn{2}{|c|}{ ASD $(n=26)$} & \multicolumn{2}{|c|}{ ASD Negative $(n=43)$} \\
\hline & Total (n) & Percentage (\%) & Total (n) & Percentage (\%) \\
\hline \multicolumn{5}{|l|}{ Age } \\
\hline 18 months $-<5$ year & 20 & 76.9 & 32 & 74.4 \\
\hline $5-<6$ year & 1 & 3.8 & 4 & 9.3 \\
\hline $6-<10$ year & 5 & 19.2 & 5 & 11.6 \\
\hline $10-<18$ year & 0 & 0 & 2 & 4.7 \\
\hline Average age $\pm S D$ (year) & $3.84 \pm 1.73$ & & $3.65 \pm 0.35$ & \\
\hline \multicolumn{5}{|l|}{ Gender } \\
\hline Male & 21 & 80.8 & 36 & 83.7 \\
\hline Female & 5 & 19.2 & 7 & 16.3 \\
\hline
\end{tabular}

Table 2. The average of the neutrophil count, lymphocyte count, and NLR $(n=69)$

\begin{tabular}{lcc}
\hline \multicolumn{1}{c}{ Laboratory Test Results } & \multicolumn{2}{c}{ Average Value } \\
\cline { 2 - 3 } & ASD (n=26) & Negative ASD (n=43) \\
\hline Absolute neutrophils count $\left(10^{3} / \mu \mathrm{L}\right)$ & $3.88 \pm 0.24$ & $4.01 \pm 0.22$ \\
Absolute lymphocytes count $\left(10^{3} / \mu \mathrm{L}\right)$ & $4.15 \pm 0.3$ & $4.24 \pm 0.21$ \\
NLR & $1.01 \pm 0.07$ & $1.02 \pm 0.06$ \\
\hline
\end{tabular}


This study found a higher number (21 patients, $80.8 \%$ ) of male subjects with ASD compared to female subjects. Most ASD subjects aged 18 months $-<5$ years (20 patients, $76.9 \%$ ) with an average age of $3.84 \pm 1.73$ years (Table 1 ).

The mean absolute neutrophil count of all subjects with ASD was $3.88 \pm 0.24 \times 10^{3} / \mu \mathrm{L}$. The mean absolute lymphocyte count was $4.15 \pm 0.3 \times 10^{3} / \mu \mathrm{L}$. The average NLR was $0.01 \pm 0.07 \times 10^{3} / \mu \mathrm{L}$ (Table 2).

Diagnostic tests were performed to determine the accuracy of NLR to diagnose ASD with a gold standard (the diagnosis was made by pediatricians using DSM-V criteria). The analysis was first carried out by determination of the Area Under Curve (AUC) and determination of the value of the intersection point. The cut-off value was then used to determine the NLR category. Diagnostic test results can be seen in the $2 \times 2$ table (Table 3 ).

Table 3. $2 \times 2$ table of NLR

\begin{tabular}{ccc}
\hline \multirow{2}{*}{ NLR } & \multicolumn{2}{c}{$\begin{array}{c}\text { Gold Standard } \\
\text { ( DSM-V criteria) }\end{array}$} \\
\cline { 2 - 3 } & Positive & Negative \\
\hline Positive $\left(\leq 7 \times 10^{3} / \mu \mathrm{L}\right)$ & 20 & 14 \\
Negative $\left(>7 \times 10^{3} / \mu \mathrm{L}\right)$ & 6 & 9 \\
\hline
\end{tabular}

The cut-off value was determined using the Youden Index and a cut-off value of 0.68 was obtained (Figure 1). The cut-off point was then used as the point to determine the positive and negative categories of NLR examination. The AUC was obtained at 0.502 . At the cut-off value of 0.68 , to diagnose ASD, the NLR showed a sensitivity, specificity, positive predictive value, negative

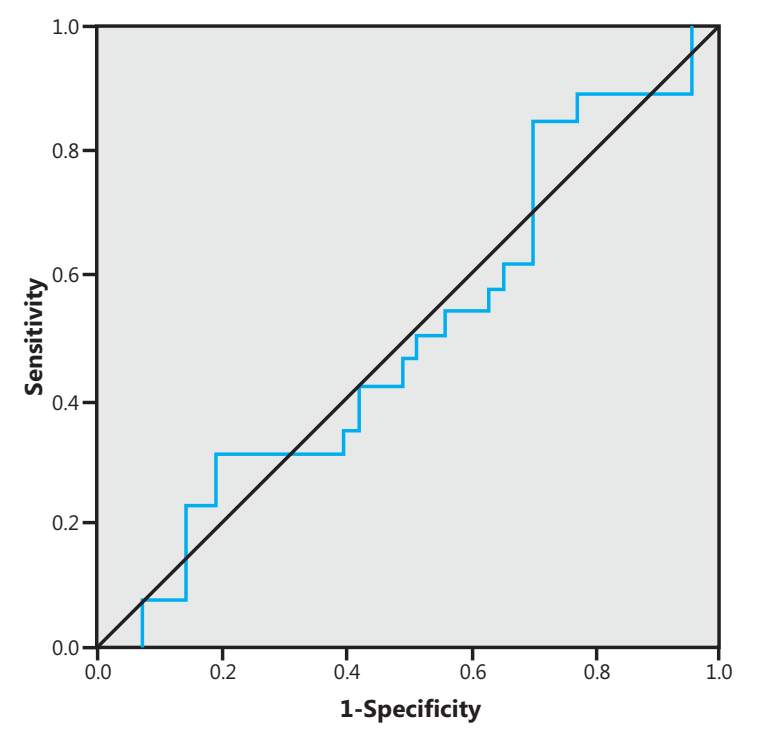

Figure 1. The cut-off value was determined using the Youden Index (0.68) predictive value, positive likelihood ratio, negative likelihood ratio, prevalence, pre-test odds, and accuracy of $84.62 \%, 27.9 \%, 41.51 \%, 25 \%, 1.17,0.55$, $37.68 \%, 1.03$, and $50.2 \%$, respectively.

In this study, it was found that the subjects with ASD mostly (76.9\%) aged 18 months $-<5$ years old, with an average age of $3.84 \pm 1.73$ years. Symptoms of ASD are usually detected at less than 2 years of age. But it can also arise after children aged between 12-24 months (regressive autism). Children with regressive autism can develop normally, speak, and responsive; however, between the ages of 12-24 months they are unable to develop, there is a regression in the communication and social interaction, less eye contact, and speech before its loss. ${ }^{21,22}$ The results of the study by Kutlu et al. showed that the average age of ASD patients was $3.43 \pm 1.03$ years. This is due to screening for ASD starting from the age of 18 months. ${ }^{23}$

Klienman et al. suggested that the ratio of males and females with ASD was close to 4:1, following this study, which found the percentage of males with ASD was $80.8 \%$ and females with ASD was $19.8 \%{ }^{24}$ This is caused by the male hormone testosterone, which plays a role in microglial genes and the production of neurotransmitters in the brain. The higher risk of oxidative stress is also found in boys. ${ }^{24,25}$

The mean absolute neutrophil count of ASD patients in this study was $3.88 \pm 0.24 \times 10^{3} / \mu \mathrm{L}$. Kutlu et al. found that the mean absolute neutrophil count was $3,450 \times 10^{3} / \mu \mathrm{L}^{20}$ Kulaksizoglu et al. found that the mean absolute neutrophil count was $4.95 \pm 2.49 \times 10^{3} / \mu \mathrm{L}^{26}$

This research found that the mean absolute lymphocyte count was $4.15 \pm 0.3 \times 10^{3} / \mu \mathrm{L}$. This was in accordance with the study of Kutlu et al., that mean absolute lymphocyte count was $3.97 \pm 1.63 \times 103 / \mu \mathrm{L}^{23}$ This finding result was slightly higher than Kulaksizoglu et al, which found the mean absolute lymphocyte count was $3.26 \pm 1.30 \times 103 / \mu \mathrm{L}^{26}$

The average NLR was $1.01 \pm 0.07$. Kutlu et al. found that the ratio was 0.96 , while Kulaksizoglu et al. found that the ratio was $1.69 \pm 0.81 .{ }^{23,26}$ Sahin et al. found that the magnitude of monocyte lymphocytes ratio in ASD patients was $1.19 \pm 0.69 .^{27}$

This study showed that the ability of NLR to diagnose ASD (sensitivity) was $84.62 \%$ and the ability of NLR to diagnose a negative-ASD child (specificity) was $27.9 \%$. The proportion of true subjects with ASD and NLR $\geq 0.68$ (positive predictive value) was $41.51 \%$, while the proportion of true subjects without ASD but with NLR $\geq 0.68$ (negative predictive value) was $25 \%$. The estimated value is influenced by the prevalence of the disease. If the disease prevalence is 
low, the positive predictive value will decrease and the negative predictive value will increase. ${ }^{28}$

The NLR of $\geq 0.68$ showed a positive likelihood ratio of 1.17; NLR $\geq 0.68$ showed a negative likelihood ratio of 0.55 . The ability of NLR to diagnose ASD (accuracy) of $50.2 \%$ was interpreted as very weak. ${ }^{28}$

The NLR is a ratio that represents 2 types of leukocytes from 2 different inflammatory pathways. Neutrophils mainly play a role in the mechanism of acute inflammation, while lymphocytes are cells that play a role in chronic inflammation. Decreased lymphocytes and increased neutrophils are characteristic of acute inflammation, and lymphocytes will increase as neutrophils will decrease if the inflammation becomes more chronic. ${ }^{23}$ The severity of ASD symptoms can also affect inflammatory parameters. The pathophysiology underlying ASD is inflammation of the brain. It is possible that inflammation of the brain is formerly acute, before subsequently develop to chronic inflammation. ${ }^{23,29}$

Autism spectrum disorder patients also have immune-specific diseases, which were only observed by researchers through a history of the patient's disease, indicating a high possibility of false positives or false negatives. Comorbidities such as infections, asthma, allergies, and skin rashes that cannot be explained are found in many ASD patients. Various non-physical comorbidities are also found in children with ASD, such as intellectual disability, Attention Deficit Hyperactivity Disorder (ADHD), and affective disorders. ${ }^{30}$

Neutrophils and lymphocytes involved in inflammation not only underlie the mechanism of ASD but also other psychiatric conditions, which are a differential diagnosis of ASD. Di Marco et al. stated that ASD and intellectual disability are based on the same mechanism as immune dysfunction. ${ }^{31}$

There are still many contradictive studies about ASD. The research by Kutlu et al. and Sahin et al. showed that there was a significant correlation between NLR and ASD, although the two studies did not support each other. Kutlu et al. stated that the NLR value in ASD patients was significantly higher than in controls, while Sahin et al. stated that the NLR value in ASD patients was significantly lower than in controls. This certainly can affect the diagnostic value of NLR. ${ }^{23,27}$

\section{CONCLUSION AND SUGGESTION}

The results of this study found that to diagnose autism spectrum disorders, the NLR ratio showed a sensitivity, specificity, positive predictive value, negative predictive value, positive likelihood ratio, negative likelihood ratio, prevalence, pre-test odds, and accuracy of $84.62 \%, 27.9 \%, 41.51 \%, 25 \%, 1.17$, $0.55,37.68 \%, 1.03$, and $50.2 \%$, respectively.

Further research by using primary data and other inexpensive and widely available inflammatory markers was needed.

\section{REFERENCES}

1. Boat TF, Wu JT. Mental disorders and disabilities among low-income children. The $1^{\text {st }}$ Ed., United States of America, The National Academies Press, 2015; 157-165.

2. Hari peduli autisme sedunia:Kenali gejalanya, pahami keadaannya. 2018 (accessed Des 7, 2019). Available at: https://www.kemenpppa. go.id/index.php/page/read/31/1682/ hari-peduli-autisme-sedunia-kenali-gejalanya-pahami-keadaannya.

3 Taylor B, Jick H, MacLaughlin D. Prevalence and incidence rates of autism in the UK: Time trend from $2004-2010$ in children aged 8 years. BMJ, 2013; 1-6

4. Arlington VA. American psychiatric association. $5^{\text {th }}$ Ed., Autism spectrum disorders, in diagnostic and statistical manual of mental disorders. Washington DC, American Psychiatric Publishing, 2013; 50-59.

5. Adam MHY, Bhismadev C, David R, Meng C, John S, Simon BC. From molecules to neural morphology: Understanding neuroinflammation in autism spectrum condition. Moleculer autism. Biomed Central, 2016; 7(9): 1-8.

6. DA Rossignol, RE Frye. A review of research trends in physiological abnormalities in autism spectrum disorders: Immune dysregulation, inflammation, oxidative stress, mitochondrial dysfunction and environmental toxicant exposures. Molecular Psychiatry, 2012; 17: 389-401.

7. Alvina Putri PS, Mohamad A, Betty L. Causes of autism disorders through the neuroinflammation pathway. Bio-experiment penyebab gangguan autis melalui jalur neuroinflamasi. Bioeksperimen, 2017; 3(2): 1-9.

8. Ningan $\mathrm{X}$, Xiaohong Li, Yan Zhong. Inflammatory cytokines: Potential biomarkers of immunologic dysfunction in autism spectrum disorders. Hindawi Publishing Corporation, 2015; 1-10.

9. Ashwood P, Krakowiak P, Hertz-Picciotto I, Hansen R, Pessah I, Van de Water J. Elevated plasma cytokines in autism spectrum disorders provide evidence of immune dysfunction and are associated with impaired behavioral outcome. Brain Behav. Immun. 2011; 25: 40-45.

10. Molloy CA, Morrow AL, Meinzen-Derr J, Schleifer K, Dienger $\mathrm{K}$, et al. Elevated cytokine levels in children with an autism spectrum disorder. J. Neuroimmunol, 2006; 172: 98-205.

11. Inga Jácome $M C$, Morales $C$, Vera Cuesta $H$, Maragoto RC, Whilby SM, et al. Peripheral inflammatory markers 
contributing to comorbidities in autism. Behav. Sci, 2016; 6: 1-29.

12. Dario S, Stephen S, Anna LB, Nicola A. Review inflammation and neuro-immune dysregulations in autism spectrum disorders. Pharmaceuticals, 2018; 11(56): 1-14.

13. Brigida AL, Schultz S, Cascone M, Antonucci N, Siniscalco D. Endocannabinoid signal dysregulation in autism spectrum disorders: A Correlation link between inflammatory state and neuro-immune alterations. Int. J. Mol. Sci, 2017; 18: 1-13.

14. Siniscalco D, Bradstreet JJ, Cirillo A, Antonucci N. The in-vitro GcMAF effects on endocannabinoid system transcriptomics, receptor formation, and cell activity of autism-derived macrophages. J. Neuroinflamm, 2014; 11: 1-8.

15. Gehan AM, Laila YA. The possible link between elevated serum levels of epithelial cell-derived neutrophil-activating peptide-78 (ENA-78/CXCL5) and autoimmunity in autistic children. Behavioral and brain function. Bio Med Central. 2015; 11(11): 1-7.

16. Ashwood P, Corbett BA, Kantor A, Schulman H, de Water JV, Amaral DG. In search of cellular immunophenotypes in the blood of children with autism. PLos One. 2011; 6(5): e19299: 1-9.

17 Özdin S, Böke Ö. Neutrophil/lymphocyte, platelet/lymphocyte and monocyte/lymphocyte ratios in different stages of schizophrenia. Psychiatry Research, Elsevier, 2019; 11: 131-5.

18. Mazza MG, Tringali AGM, Rossetti A, Botti RE, Clerici M. Cross-sectional study of neutrophil-lymphocyte, platelet-lymphocyte and monocyte-lymphocyte ratios in mood disorders. General Hospital Psychiatry, Elsevier, 2019; 58: 7-12.

19. Zekiye C, Emel U, Nefise O, Kader U. Comparison of neutrophil-to-lymphocyte, platelet-to lymphocyte, and monocyte-to-lymphocyte ratios in patients with schizophrenia, bipolar disorder, and major depressive disorder. Int J Med Biochem, 2018; 1(3): 106-10.

20. Tural HS, KasakM, $C_{1}$ tak AN, Ceylan MF. High monocyte level and low lymphocyte to monocyte ratio in autism spectrum disorders. International Journal of Developmental Disabilities, 2017; 65(2): 73-81.

21. Jennifer $H E$, Consuelo MK, Susan NB, Margaret $A$. Clinical impact of early diagnosis of autism on the prognosis and parent-child relationships. Psychology Research and Behavior Management, 2017; 10: 283-92.

22. SA Nugraheni. Menguak belantara autisme. Buletin Psikologi. Fakultas Psikologi Universitas Gadjah Mada, 2012; 20(1-2): 9-17.

23. Kutlu A, Cevher BN. Does increased neutrophil-lymphocyte ratio predict autism spectrum disorder?. Anadolu Psikiyatri Derg, 2018; 19(6): 607-14.

24. Kleinman JM, Robins DL, Ventola PE, Pandey J, Boorstein $\mathrm{HC}$, et al. The modified checklist for autism in toddlers: A follow-up study investigating the early detection of autism spectrum disorders. Journal of Autism and Developmental Disorders, 2008; 38(5): 827-39.

25. Parker W, Hornik CD, Bilbo S, Holzknecht ZE, Gentry L, Rao $R$ Nevison CD. The role of oxidative stress, inflammation and acetaminophen exposure from birth to early childhood in the induction of autism. Journal of International Medical Research, 2017; 45(2): 407-38.

26. Sibel K, Cem K. High neutrophil to lymphocyte ratio and low mean platelet volume level in autism spectrum disorders. Annals of Medical Research, 2019; 26(10): 2382-5.

27. Şahin, N. Evaluation of neutrophil/ lymphocyte ratio in children with autism and the relationship between autism severities. Psychiatry and Clinical Psychopharmacology, 2018; 28: 23-38.

28. Dahlan, Sopiyudin M. Besar sampel dan cara pengambilan sampel. Jakarta, Salemba Medika, 2013; 1-8.

29. Yenkoyan K, Grigoryan A, Fereshetyan K, Yepremyan $D$. Advances in understanding the pathophysiology of autism spectrum disorders. Behavioral Brain Research, 2017; 331: 92-101.

30. Li Q, Zhou JM. The microbiotagutbrain axis and its potential therapeutic role in autism spectrum disorder. Neuroscience, 2016; 324: 131-39.

31. Di Marco B, Bonaccorso CM, AloisiE D'Antoni, Catania MV. Neuro-inflammatory mechanisms in developmental disorders associated with intellectual disability and autism spectrum disorder: A neuro-immune perspective. CNS \& Neurological Disorders-Drug Targets, 2016; 15: 448-58. 